\title{
O planalto e a estepe, de Pepetela
}

\author{
Kelly Cristina Oliveira de Araújo \\ Universidade de Paris III
}

Planalto e a Estepe $e^{1}$ conta uma história de amor. Um amor vivido em sua plenitude no tempo curto, mas que permeia 35 anos da vida do protagonista. É no intervalo da vivência desse amor que a história acontece.

No subtítulo do livro lê-se "Angola, dos anos 60 aos nossos dias", uma informação sobre o período em que se desenvolverá a narrativa; e depois "A história real de um amor impossível", que apresenta em si uma relação de equilíbrios contrapostos, onde realidade e impossibilidade representam incompatibilidades que se harmonizam.

O livro é regido primordialmente pelas geografias dos espaços ocupados pelo narrador ao longo do tempo. Como sugere Paul Ricoeur, a narrativa do gênero romance cria uma relação entre a temporalidade vivida na ficção e o tempo que vive o mundo. Pepetela não faz menção a datas, não precisa anos, ou seja, não faz uso do calendário para contar a história, e o leitor é situado no tempo através dos acontecimentos históricos.

A importância das paisagens revela-se no título do livro. Os deslocamentos, e os lugares descritos e apropriados, assim como em outras obras de Pepetela, ritmam a narrativa. Paisagens propícias, disse Ruy Duarte de Carvalho: "As paisagens que dariam acesso a tudo o que cada um poderá descobrir dentro de si mesmo, assim, seriam aquelas que o sujeito conhece por ter de alguma maneira experimentado nelas - ou por intermédio do acesso que lhes teve - sentimentos seus ou alheios, de uma grande intensidade".

Assim, ao contrário, por exemplo, da Huíla ou de Moscou, a descrição de Argel pareceu burocrática, denotando pouco envolvimento com o lugar. Ou a ida

1. São Paulo: Ed. Leya, 2009. 
a Ulan Bator, cidade vista de relance, que permaneceu na alteridade como uma paisagem não vivida. E ainda Cuba, que nos aparece como um lugar inquieto, na imagem das ondas explodindo nas pedras e no vento que sopra do Norte.

O lugar escolhido para abrigar o nascimento do protagonista é o território Sul de Angola, mais especificamente o Lubango, um território pouco explorado até então pelo autor. O primeiro capítulo, "Os Rochedos da Tundavala", conta a infância do narrador na Huila, e transmite a inocência da Idade de Ouro, um tempo em que a importância estava na estima dos pastores pelos seus bois ou no agridoce do fruto do mirangolo.

É quando dá-se a conhecer que o narrador é branco, filho de um migrante português de vinda recente, e uma mãe com ascendentes na Madeira, de uma migração mais antiga. Eram brancos pobres, viviam numa espécie de zona de transição entre os brancos colonos ricos e os negros submetidos, e essa aparece como a primeira dualidade do livro, permeado delas, aqui entendidas como existência separada e normalmente antagônica de duas entidades contiguas.

Confrontado com o racismo, o narrador-protagonista é jogado para fora da Idade do Ouro, e vai elaborar a primeira reflexão sobre este tema que serpenteará todo o livro: "O racismo havia de me perseguir a vida inteira, como vos explicarei!"”.

As questões raciais, assim como as étnicas, estão na base da discussão sobre a construção de uma identidade nacional angolana promovida pelo MPLA (Movimento Popular de Libertação de Angola), o movimento com menor cariz étnico-regional na raiz de sua formação. Uma vez que a temática da construção da nacionalidade é uma constante na obra de Pepetela, o problema do racismo será uma constante.

Tendo já declarado, em entrevista a Michel Laban, o impacto que sofreu na infância ao perceber que a cor da pele separava as pessoas, Pepetela empresta esta passagem de sua vida ao personagem narrador do livro. Nascido no verde do planalto, onde a partir da Tundavala podia ver o ocre do deserto e crescido na duplicidade que se dá entre a fixidez das pedras e a mobilidade dos bois, o narrador forma seu caráter como um branco africano, subversivo aos olhos do sistema colonial que pregava o panracialismo, mas que se apoiava na tríade salazarista "Um Estado, uma Raça, uma Civilização".

Perseguido desde muito cedo pela polícia política de Salazar, ele ignora a origem das desconfianças a seu respeito. Mas, é a própria perseguição que o 
leva a procurar um padre na tentativa de compreender o que de fato se passava, ou o que chamou de "conceito de desigualdade natural entre os homens". Após uma sequência de questionamentos e reflexões, formula que assinalam um aprendizado e, consequentemente, uma ruptura com o tempo anterior "As saudades não vencem o medo"; "O homem só gosta da diferença, sobretudo a que o favorece"; "A cabeça cresce com as verdades que nela entram". Marcam a construção da personalidade e do caráter do personagem, e o conduzem pelo caminho que o levará ao nacionalismo angolano.

Ao enunciar "Quando se faz o indesejado, só resta sonhar", dá-se inicio ao percurso do protagonista em sua "grande viagem". Chegando a Lisboa para cursar a universidade, integra-se aos grupos contestatários do colonialismo que já existiam na Casa dos Estudantes do Império. Coincide, portanto, com o início da luta armada em Angola, em 1961.

E com "Quando se faz o indesejado, só resta sonhar", se inicia o percurso de sua "grande viagem". Chegando a Lisboa para cursar a universidade, integra-se aos grupos contestatários do colonialismo que já existiam na Casa dos Estudantes do Império. Coincide, portanto, com o início da luta armada em Angola, em 1961. No princípio de sua busca pela nacionalidade, conhecemos seu nome: Júlio Pereira, "um branco quase louro era angolano e queria lutar pela independência" (p.33).

"Os continentes são convenções, apenas existem terras separadas por mares" (p.30). Assim, o protagonista abandona Lisboa rumo à construção da nação angolana. No Marrocos, a primeira paragem, descobre que "os mais claros ainda não eram suficientemente angolanos para arriscarem a vida na luta pela Nação, pelo menos havia dúvida quanto a sua nacionalidade. E utilidade". Ele então vai para Moscou com uma bolsa de estudos; ali encontra outros africanos e forma grupo com um senegalês, um tanzaniano e um congolês. A comunicação inicial se dá por mímicas, uma vez que cada um fala uma língua (a do colonizador) diferente, e depois passam a usar o russo como língua de comunicação. O grupo pode ser visto como uma caricatura da diversidade que existe no continente africano, e que é forçosamente, pelos desígnios impostos pela história, mediado por um elemento externo à África. Ainda assim, entre os quatro africanos havia dois que eram muçulmanos, e a religião aparece como a segunda dicotomia abordada por Pepetela, um fator para clivagem. Firmou-se a aliança mais forte entre 
Júlio, o angolano, e Jean Michel, o congolês, próximos também geograficamente em suas origens.

"A verdade é dura, sempre". É Jean Michel que lhe adverte para não discutir com as ideologias soviéticas, chama atenção para os problemas internos à URSS, conta sobre a manipulação dos partidos comunistas. Começa a desconstrução das crenças político-ideológicas de Júlio. O ano era 1964, Brejnev subia ao poder.

"No entanto, na cabaça da manteiga não se faz bidromel

Nem as vacas nem as abelhas deixariam"

É através desta reflexão simbólica e poética que o autor nos apresenta as incompatibilidades dos sabores da manteiga e do hidromel. É o início do amor de Júlio e Serengerel, filha do Ministro da Defesa da Mongólia, membro do bureau político do Partido comunista local. E o namoro entre os dois é mantido em segredo.

"Ele pressentia o perigo de trocar as cabaças

Felizmente, não avistava abelhas nem vacas.

Ali.

\section{Afinal estavam bem perto"}

A imobilidade soviética quando chamada a tomar decisões que a colocassem numa possível situação de conflito é abordada no caso particular de Júlio. Tendo engravidado Serengerel, e diante da recusa absoluta da família dela em aceitar um não mongol como seu esposo, Júlio busca todas as instâncias políticas acessíveis, e se descobre desamparado. Pior do que isso, seu caso de amor - malfadado por causa de mais um racismo que se the atravessa o caminho - foi parar no meio do conflito sino-soviético. A situação geográfica da Mongólia, que se havia aliado à União Soviética, tornava o país um importante aliado estratégico. “(...) tudo era político, mesmo o amor entre dois jovens. Tudo era politico” (p. 155).

O clamor à solidariedade afro-asiática foi outra decepção. As respostas burocráticas repetiam-se "num claro desrespeito pelo espírito de Bandung, Indonésia, 
onde se criara nos anos cinquenta a tal organização unindo os dois continentes numa conferência que ficaria famosa" (p.78), como diria Salim, o tanzaniano do grupo dos quatro. Vencem as dicotomias, que continuam sem serem quebradas.

\section{"Nas fábulas da vida, algumas misturas são intoleradas"}

Terminado o curso superior em Economia em Moscou, Júlio parte para o treino de guerrilha no Sul da Rússia, e de lá para Argélia. O racismo outra vez - o mesmo que o enviou para URSS - o prendeu em Argel, atuando como economista para o Estado argelino em nome do MPLA.

Chegou o dia em que Júlio foi mandado ao front da guerrilha. E foi justo para Cabinda, respirar o Mayombe que já foi o espaço do desenrolar de outro romance de Pepetela. É na floresta cerrada que o narrador vive a experiência da alteridade entre aqueles que lutam para ter o mesmo país, para fazer parte da mesma nação. E pela construção da identidade nacional, Júlio cede às crenças dos soldados de seu batalhão e se diz imortal frente à bala dos inimigos, graças ao feitiço de um kimbanda congolês. Ele é um galho que verga com os ventos, na busca da conciliação, e serve como ponte entre vários mundos, aproximando-os. Escolhe "Alicate" como nome de guerra - uma homenagem aos africanos do sul de Angola que eram "batizados" com nomes de objetos diante da dificuldade da pronúncia de seus nomes verdadeiros -, mas que também pode ser interpretado como o instrumento que retorce, verga, entorta.

Vêm a independência, em 1975, a construção do Estado nacional, e o processo de sua consolidação ocorre concomitante à guerra civil. Júlio é militar, sobe a general. Nunca esquece Serengerel e a filha. No entanto, nem mesmo o contato direto com os assessores soviéticos - que eram mandados a Angola para assistirem os dirigentes em suas decisões, principalmente militares -, propiciou informações de sua família mongol, como as chamava.

Os anos passam no pós-independência sem que o narrador dê muitos detalhes sobre os acontecimentos históricos. A abordagem do período enfatiza a desilusão em relação ao marxismo-leninismo, ao socialismo soviético, e a consequente hipocrisia que se estabelece nas relações entre os dois países, chegando a proclamar que os angolanos "sempre fomos considerados falsos revolucionários e muitas vezes a realidade dava razão aos críticos", "socialistas só de boca".

Numa conversa com seu assessor soviético, há uma longa interpretação so- 
bre a política da Perestroika, de Gorbatchev, sobre o seu falhanço que arrastava a URSS para o colapso final; e ainda sobre a abertura econômica gradual de Angola, estabelecendo contatos com países com quem até então não mantinha relações, como os EUA. Inferimos estar próximo a 1990, e o narrador conta-nos de suas aventuras, enquanto chefe da logística militar do Exército angolano, pelo mundo da venda de armas, das comissões, da corrupção, dentro e fora de Angola. A crise do Estado angolano, que se exacerba após a adoção da economia neoliberal, já havia sido tratada por Pepetela no livro A geração da utopia, no qual evidenciara a sua descrença no modelo político-econômico adotado e as poucas perspectivas de transformação da realidade social minada pela corrupção.

Em O planalto e a estepe, Pepetela atualiza os problemas internos abordados no livro de 1992, focalizando a ligação da corrupção por tantos setores, agora que já não há mais guerra, como as telecomunicações. E aponta a falta de união entre os países africanos, cujas elites estiveram, e permanecem, de costas para o continente.

Cuba entra na história trazendo Serengerel, 35 anos depois, de volta para Júlio, e levando-a até Angola para viverem ali o amor.

Disse Júlio que "Desde o nascimento percebi ser um joguete nas lutas entre forças desconhecidas", mas, é verdade que quase todo o mundo descolonizado no pós-II Guerra Mundial o foi, e ele viveu como parte desse contexto maior, uma porção da história, o paradigma de uma geração.

O tempo dos acontecimentos históricos não é o mesmo tempo vivido do amor. Estes foram anos de grande aceleração histórica em Angola e no mundo, que viveu o temor da Guerra Fria, das bipolaridades, dos conflitos locais. Júlio foi tragado por esse tempo, consumido por ele, nele.

Impiedoso foi o tempo das guerras e das ideologias para com o amor. Proporcionou a improbabilidade da paixão entre um angolano, do planalto, e uma mongol, das estepes, no leste europeu, para, em seguida, decretar a impossibilidade da vivência do amor entre eles. O amor correu por fora, em paralelo, com sobresaltos, intervalos, separações, subestimado pela experiência histórica totalizante. Mas, como para se redimir, o tempo foi complacente com Júlio e Sarangerel, e os permitiu viverem juntos na geografia da paisagem de Angola, partilhando as transumâncias a que foram forçados até o reencontro, e o fim.

Recebido em 09 de Abril e aprovado em 08 de maio de 2010. 